\title{
CORPO E POLÍTICA NO RETORNO À DEMOCRACIA NO URUGUAI (1985-1990): INTEGRAÇÃO DA SOCIEDADE E CONTINUAÇÃO DA VIOLÊNCIA
}

\author{
BODY AND POLITICS IN THE RETURN TO DEMOCRACY IN URUGUAY: \\ (1985-1990) THE INTEGRATION OF SOCIETY AND PERSISTENT \\ VIOLENCE \\ CUERPO Y POLÍTICA EN EL RETORNO A LA DEMOCRACIA EN URUGUAY \\ (1985-1990): INTEGRACIÓN DE LA SOCIEDAD Y CONTINUACIÓN DE LA \\ VIOLENCIA
}

Cecilia Seré*, Alexandre Fernandez Vaz ${ }^{* *}$

Palavras-chave

Corpo.

Política.

Uruguai.

Educação.

Keywords

Body.

Politics.

Uruguay.

Education.

Palabras clave

Cuerpo.

Política.

Uruguay.

Educación.
Resumo: Analisa relações entre política e governo do corpo no retorno à democracia no Uruguai, após a última ditadura cívico-militar (1973-1985). No período, diversas propostas para o desenvolvimento da Educação Física, esporte e recreação surgiram com pretensão inovadora, mudando formas e procurando integrar uma sociedade politicamente fragmentada. Porém, a tentativa de aplacar os efeitos políticos das propostas corporais revela sinais de continuidade com a ditadura, evidenciando semelhanças no governo do corpo entre os regimes.

Abstract: This paper analyzes the relationship between politics and the governing of the body in the return to democracy in Uruguay, following the last civilian-military dictatorship (1973-1985). During this period, various innovative proposals emerged seeking to change their approach to the development of Physical Education, sport and recreation and trying to integrate a fragmented political society. However, the attempt to downplay the political effects of bodily practices signals continuity with the dictatorship, bringing to light similarities between both political regimes' governing of the body.

Resumen: Este artículo analiza relaciones entre política y gobierno del cuerpo en el retorno a la democracia en Uruguay, luego de finalizada la última dictadura cívico-militar (1973-1985). En el período, diversas propuestas para el desarrollo de la Educación Física, deporte y recreación surgieron con pretensión innovadora, cambiando sus formas y procurando integrar una sociedad políticamente fragmentada. Sin embargo, la intensión de aplacar los efectos políticos de las propuestas corporales devela señales de continuidad con la dictadura, evidenciando semejanzas en el gobierno del cuerpo entre regímenes.
* Universidad de la Republica, Uruguay.

E-mail: serececilia@gmail.com

** Centro de Ciências da Educação, Universidade Federal de Santa Catarina, Florianópolis, SC. E-mail: alexfvaz@uol.com.br

Recebido em: 30-06-2014 Aprovado em: 25-08-2014 (c) (i) () Licence 


\section{INTRODUÇÃO': CORPO, POLÍTICA E DEMOCRACIA}

A saída da ditadura, que vai de 1973 a 1985, e o processo de redemocratização que se inicia no Uruguai na década de 1980 foi um tempo de tensas mudanças, de grandes transformações nacionais, políticas, econômicas e sociais. Como em outros países da América Latina, o retorno à democracia se apresentou no Uruguai como uma transição negociada entre militares e alguns dos partidos políticos tradicionais, dando forma ao que, em parte, caracterizaria o governo posteriormente eleito que predicava a "união nacional" e o "câmbio em paz". Foi uma restauração que proclamava um retorno a um passado idealizado como perdido e melhor, anterior à ditadura e a ser recuperado em valores como democracia, liberdade, tolerância e pluralismo. Correspondia a tal passado um futuro de promessas que se confrontava com os desequilíbrios econômicos, políticos e sociais e, especificamente, com as recorrentes violações aos direitos humanos (BUQUET, 2003).

Essa situação de tensões e mudanças, cuja ruptura em termos institucionais se apresenta em 1985 com a posse de novos governantes eleitos diretamente (mesmo com pessoas e partidos políticos ainda proscritos), constitui cenário propício para a pergunta sobre a política contemporânea no país. Frente a uma sociedade que de fortemente implicada na vida política nacional com as revoltas sessentistas e as lutas pelo retorno à democracia, passou a despolitizar-se com o fim da ditadura, e frente ao paradoxal movimento de a política voltar à vida pública depois de quase doze anos de governo ditatorial, mas que tende a ser reduzida à administração estatal, o panorama que se abre na década de 1980 torna-se terreno fértil para o entendimento do contemporâneo recuo político e seus efeitos sobre o corpo.

O presente artigo dedica-se a esse contexto, percorrendo discursos estatais que tiveram no corpo seu desiderato, alcançando com isso formas em que a política contemporânea se configura. Para tanto, analisamos documentos elaborados pela Comisión Nacional de Educación Física (CNEF) entre 1985 e 1990, órgão nacional encarregado da promoção e organização de diversas atividades de Educação Física, esporte e recreação no país. Selecionamos revistas e propostas curriculares elaborados pela CNEF que foram arqueologicamente confrontados com documentos de outros órgãos governamentais. Adentrando essas discursividades, procuramos identificar pontos de encontro e dispersão, disputas e consensos, referenciando-os no interior das condições políticas, sociais e históricas nas quais foram possíveis tais enunciações.

O período selecionado (1985-1990), denominado por diversos historiadores (entre outros, CAETANO, 2005, CAETANO; RILLA, 1987) como de "transição democrática", começa com a posse de Julio María Sanguinetti na presidência da República em 1985, e abarca a totalidade de seu mandato, momento de grande efervescência política e de forte reorganização nacional. Finaliza não só com a conclusão do governo de Sanguinetti, mas também com a ratificação da Ley de Caducidad de la Pretensión Punitiva del Estado (RICO, 2005).

10 trabalho apresenta parte dos resultados da dissertação de mestrado "Políticas do corpo e governo da cidade: do retorno à vida democrática na cidade de Montevidéu - Uruguai", defendida no Programa de Pós-graduação em Educação da Universidade Federal de Santa Catarina. A pesquisa, realizada com apoio do CNPq (bolsa PEC-PG, processo 190366/2011-7) se articula com as atividades desenvolvidas no Núcleo de Estudos e Pesquisas Educação e Sociedade Contemporânea (UFSC/CNPq Programa de Pesquisas Teoria Crítica, Racionalidades e Educação, IV) e no Grupo Políticas Educativas y Políticas de Investigación en Educación Física (GPEPI/ISEF/UdelaR). Uma versão reduzida deste trabalho foi apresentada nas XXII Jornadas de Jovens Pesquisadores organizada pela Asociación de Universidades Grupo Montevideo (AUGM), realizadas na Universidad de Playa Ancha (Valparaíso/Chile) entre 29 de setembro e 1 de outubro de 2014.

2 Órgão do Poder Executivo criado em 1911 com o objetivo de desenvolver a "cultura física" do país, funcionou até junho de 2000 , sendo substituído pelo Ministerio de Deporte y Juventud (a partir de 2005 Ministerio de Turismo e logo Ministerio de Turismo y Deporte). 
O trabalho se organiza em dois momentos. Começa apresentando uma correlação entre as formas de intervenção sobre o corpo durante o período de governo ditatorial, esboçando as novidades programáticas que se anunciaram com o retorno da democracia depois de 1985. Formas de apresentação do corpo, organização das aulas e exibições ginásticas conformam uma espetacularização do corpo que se atenua com a mudança de regime. Uma integração da sociedade se proclama como necessária, e constitui o tema de análise a seguir. A exaltação de praças públicas para o exercício físico da cidadania parece ser a inovação da CNEF com o fim do regime cívico-militar, promovendo a participação voluntária e abrangente de toda a população, procurando superar as diferenças políticas que dividiam a sociedade. Não sem consequências políticas deve ser considerado este movimento que privilegia o corpo como mecanismo silenciador da palavra na vida pública e atenua as diferenças políticas, unificando a sociedade pela via da redução da população a mero conjunto de organismos vivos.

\section{DA ESPETACULARIZAÇÃO DO CORPO À INTEGRAÇÃO DA DIFERENÇA: NOVAS PROPOSTAS DE EDUCAÇÃO FÍSICA PARA UM NOVO URUGUAI}

Quase doze anos de governo ditatorial não finalizam de forma definitiva com as eleições diretas. A mudança de regime, o fim da ditadura e a redemocratização do Uruguai a partir da década de 1980 não representaram uma ruptura radical e um afastamento definitivo das dinâmicas do governo de exceção. Seu caráter de "processo" e sua configuração como "transição negociada" foram algumas das particularidades que asseguraram diversas continuidades entre uma e outra forma de organização política. Mesmo sendo significativa a posse das autoridades legitimamente eleitas em 1984, não se pode negar o prosseguimento de características próprias do governo ditatorial.

Tomando como eixo de análise o corpo, e especificamente as intervenções sobre ele no âmbito da Educação Física, esporte e recreação, é possível observar mudanças nas propostas elaboradas pela Comisión Nacional de Educación Física, porém nem sempre supondo uma ruptura radical com as formas próprias de uma política ditatorial. Permanece algo no seio da estrutura programática, o que torna necessário abordar brevemente formas com que o corpo foi articulado nas intervenções do governo cívico-militar, um dos períodos mais obscuros da história uruguaia do século XX.

Com um forte caráter repressivo, a ditadura instalada no Uruguai entre 1973 e 1985 utilizou diversas estratégias que se anunciavam como para o "desenvolvimento do país". Dentre as formas repressivas na vida pública, interessa-nos salientar os efeitos sobre o corpo perpetrados pelo regime.

Uma análise dos procedimentos da Comisión Nacional de Educación Física, permite observar que, no contexto da ditadura, para além das intervenções militares que podemos considerar como de força sobre o corpo (exercício da violência, física ou simbólica: repressões, torturas, desaparecimentos, perseguições, agressões e vigilâncias permanentes), existiu toda uma rede de ações que procurou desenvolver uma força do corpo, valendo-se do poder do espetáculo, da uniformização da presença, da potência da estética das intervenções corporais,

orden constitucional, ha caducado el ejercicio de la pretensión punitiva del Estado respecto de los delitos cometidos hasta el $1^{\circ}$ de marzo de 1985 por funcionarios militares y policiales, equiparados y asimilados por móviles políticos o en ocasión del cumplimiento de sus funciones y en ocasión de acciones ordenadas por los mandos que actuaron durante el período de facto." (URUGUAY, 1986). 
da normalização e moralização especificamente da juventude "Oriental"4. Podem ser salientadas atividades ginásticas e esportivas realizadas em espaços públicos, assim como aulas de Educação Física nas escolas, o detalhe na disciplina, nas formações, vozes de comando, exigências sobre o corpo que traduziam sinais do regime.

Nessas intervenções sobre o corpo durante o governo cívico-militar, a CNEF tinha uma importante presença, numa forma de atuação que facilmente pode ser identificada com o que Foucault (1997) chamou de "quadros vivos". Estes classificam, ordenam, regularizam indivíduos e condutas, corpos e movimentos, distribuição disciplinar da qual se espera obter, como diz Foucault (1997), o maior número de efeitos possível. O ordenamento de multidões confusas era meta da CNEF, facilitando a instauração de uma estética corporal militar traduzida na grafia do esporte e da ginástica.

O regulamento do corpo docente da CNEF em 1974, no qual se descreve detalhadamente o que se espera do professor de Educação Física, para o caso de "aptidão física e presença" estabelece qualificações entre 0 e 12, conforme o "ideal esportista" que se deve atingir. Dentre essas qualificações podemos destacar:

Grado 0: Presencia física obesa, cabello largo y desalineado, sin afeitar, equipo no reglamentario y poca pulcritud [...]

Grado 6: Se mantiene en forma permanente en buena aptitud física, su porte personal y uniforme es correcto [...]

Grado 9: Su estado físico, su apostura, presencia personal con su respectivo uniforme y su atildamiento, se destacan por su sobriedad y regularidad (COMISIÓN NACIONAL DE EDUCACIÓN FÍSICA, 1974 apud RODRÍGUEZ GIMÉNEZ, 2003, p. 104).

Por outro lado, é importante considerar que, em 1973, e com a aprovação da Ley General de Educación (URUGUAY, 1973), a Educação Física ingressa no sistema de ensino obrigatório nas fases que correspondem ao Lensino médio básico[ (jovens de entre 12 e 15 anos aproximadamente). Porém, a disciplina não ingressava como $\square$ Educação Físical, senão por meio da obrigatoriedade da $\square c u l t u r a$ físical, incentivando (el deporte y las actividades recreativas (URUGUAY, 1973). Dentre os conteúdos a serem ensinados, era a nomeada $\square$ Bolilla $5 \square$ (CONSEJO NACIONAL DE EDUCACIÓN, 1980) que explicitamente traduzia a tradição militar de marchas e formações aos alunos. Com esse nome se designava a Unidade de conteúdos da proposta curricular de Educação Física na qual se abordavam formações e vozes de comando, reproduzindo a estética militar de apresentação do corpo e de organização da aula: clase, formación, columna, fila, alineación, intervalo, distancia, posición de firmes, posición de descanso eram algumas das terminologias utilizadas para ministrar o conteúdo 5 .

A eficiência e a ordem eram procuradas sem perda de tempo:

1- Clase; 2- Atención. A la voz ejecutiva, los alumnos adoptarán la posición de firmes, en el lugar que se encuentren, dando frente al profesor [...] 1- En una fila. 2- A formar. A la voz ejecutiva, los alumnos pasan a colocarse al costado de la base; cuando la clase se encuentra en esta situación, el profesor mandará alinear por el lado que designó la base. Fiscalizará la alineación y una vez terminada ésta

4 A referência à orientalidade, que começa antes da ditadura, supõe uma oposição ao marxismo, demarcando sua diferença com os partidos tradicionais da política uruguaia (DEMASI, 2013). 1975 foi declarado "Año de la Orientalidad", procurando-se resgatar valores "tradicionais" que salvaguardassem ao Uruguai das "contaminações subversivas forâneas" (CAETANO; RILLA, 1987). Sobre a relação da CNEF com o Ano da Orientalidade, consulte-se Bailón (2007). 
mandará: Firmes. (CONAE, 1980, p. 4) [...] Cuando el profesor da por terminada la clase y quiere hacer retirar a sus alumnos, manda: 1- Rompan Filas [...]. A la voz ejecutiva los alumnos dan un paso al frente con el pie izquierdo unen enérgicamente el derecho a éste y abandonan la formación con el mayor orden posible (CONSEJO NACIONAL DE EDUCACIÓN, 1980, p. 6)

As aulas de Educação Física nas instituições de ensino médio se impregnavam dessa dinâmica própria do militar, analisando detalhes, procurando uniformidades, reproduzindo uma estética típica das formações e disposições marciais que procuravam normalizar e moralizar a juventude do país.

Outro aspecto significativo dessa difusão das formas militares durante o período ditatorial pode ser observado nos espetáculos ginásticos realizados em estádios esportivos (em Montevidéu principalmente no Estádio Centenario e no Estádio Peñarol), assim como os desfiles nas principais avenidas das cidades (a Avenida 18 de julio foi o principal cenário dessas exibições na capital do país), sinal do controle e domínio do corpo. Esta coordenação de movimentos que transmitia uma sensação de unidade e de sincronização de esforços, se configurava como mais uma estratégia de propaganda do regime militar, para o qual se convocavam grupos de exibição formados por ginastas, estudantes e docentes do Instituto Superior de Educación Física (ISEF), principal centro nacional de formação de profissionais no âmbito da Educação Física. Exemplo da disciplina e dos corretos modos de uso do corpo, os espetáculos organizados pela CNEF procuravam revitalizar as "forças morais" mostrando os efeitos "formativos" e "saudáveis" que adviriam do bom exercício do corpo (COMISIÓN NACIONAL DE EDUCACIÓN FÍSICA, 1976). Porém as demonstrações não se esgotavam em sua realização. Os benefícios da câmara filmadora fazia com que esses rituais pudessem ser repetidos e rememorados para manter latentes as mensagens moralizantes que esperavam transmitir. Os espetáculos ginásticos e desfiles organizados pela CNEF eram filmados e compilados nas edições de Uruguay Hoy, noticiários quinzenais antecedendo a programação cinematográfica, entre 1979 e 1984, que propagandeavam os acontecimentos ao gosto do governo ditatorial, a cargo da Dirección Nacional de Relaciones Públicas (DINARP) (MARCHESI, 2001).

Entre a repressão, marcada pelas prisões, torturas e desaparecimentos, até a tecnologia política do disciplinamento e a militarização detalhada, desenvolveram-se as formas mais evidentes de ação sobre o corpo durante a ditadura. Porém, o retorno democrático fez com que tais exigências de exibição e perfeição corporal se atenuassem, e em 1987 a CNEF rejeitou a possibilidade de realizar um espetáculo ginástico que fora solicitado pelas autoridades da $\mathrm{Fe}$ deración Uruguaya de Fútbol. 0 pedido respondia à vontade de realizar uma solenidade antes de uma partida da Seleção Uruguaia de Futebol, contando com um festival ginástico realizado com alunos das praças de esportes, a Federación Uruguaya de Gimnasia e Ialguna otra Federación cuya actividad permitiera la realización de exhibiciones ${ }^{6}{ }^{6}$. Ainda que a CNEF desejasse deixar manifesta a disposição da Comisión para a realização do ato ginástico, declara não ser "conveniente la realización de la exhibición dado que no se cuenta con el elemento humano suficiente para ello."7. Insuficiência de recursos ou aceitação insuficiente? A espetacularização do corpo como elemento de distinção do regime militar foi perdendo visibilidade no espaço público, e as demonstrações e desfiles que mostravam um corpo militarizado foram reduzidas

6 Atas da Comisión Nacional de Educación Física de 1987. f. 77756 (não publicadas)

7 Atas da Comisión Nacional de Educación Física de 1987. f. 77756 (não publicadas) 
a espetáculos propriamente militares, frequentemente em atividades com a presença de autoridades públicas ${ }^{8}$.

Com o retorno à democracia uma nova proposta de intervenção se fazia presente na CNEF. Entre 1985 e 1990 a Comisión elaborou um conjunto de documentos nos quais se evidenciam mudanças nas formas de promover atividades físicas para a população. Uma revista publicada em 1990, intitulada El Deporte, la Educación Física y la Recreación. Marzo 1985 - Marzo 1990 e que contou com a edição de apenas número, divulgava os resultados atingidos no período, salientando diversas modificações em infraestrutura urbana em prol do fomento esportivo, assim como propagandeava os programas de ação realizados naqueles anos (COMISIÓN NACIONAL DE EDUCACIÓN FÍSICA, 1990). A partir da realização de um Seminario de Diseño Curricular y Programación de la Educacion Física, entre janeiro e abril de $1986^{\circ}$, foram elaborados quatro Programas Curriculares (Programa de Educación Deportiva, Programa de Educación Física nivel escolar, Programa de Educación Física nivel medio, Programa de Recreación) distribuídos e implementados a partir de 1989, sob o lema de um Nuevo Modelo de Educación Física (COMISIÓN NACIONAL DE EDUCACIÓN FÍSICA, 1990, p. 42).

Com a elaboração desses quatro Programas Curriculares, a CNEF fazia a opção pela intervenção em ambientes não formais da Educação Física, promovendo uma mudança de papel do professor, tendendo ao "abandono de la tradicional clase de gimnasia, sustituida por modalidades más atrativas y de mayor efecto multiplicador e igual poder educativo" (SOTELO FARIÑA, 1985 apud COMISIÓN NACIONAL DE EDUCACIÓN FÍSICA, 1988a, p. 3). A proposta dessa nova visão para a Educação Física esperava ocupar a cidade com diferentes atividades recreativas e esportivas que abarcariam a totalidade da população, mas sabendo que o público alvo principal seriam os setores vistos como carentes. Principalmente nas praças de esportes ${ }^{10}$ e, durante o verão, nas praias da capital, se desenvolveram programas de promoção de atividades físicas. Da ginástica ao esporte e à recreação, e com uma "educación física infantil en sustitución de una educación física escolar", isto é, com uma Educação Física não limitada às instituições escolares, a CNEF fazia uma opção "não formal" em Educação Física, promovendo uma nova fórmula para uma nova etapa do Uruguai. A coletividade devia se deparar com as propostas de Educação Física que seriam desenvolvidas em diferentes espaços da cidade, nos "terrenos baldíos, los espacios verdes, las plazas y las playas." (COMISIÓN NACIONAL DE EDUCACIÓN FÍSICA, 1988b, p. 3).

O retorno democrático para a Educação Física chegou com um discurso inclusivo, que procurava atividades "atraentes" que favorecessem a participação voluntária de todos os cidadãos, mas conforme assinalava Sotelo Fariña, com o mesmo poder educativo (COMISIÓN NACIONAL DE EDUCACIÓN FÍSICA, 1988a). Na revista publicada em 1990 são evidenciadas as formas de intervenção escolhidas pela CNEF para a sociedade pós-ditadura:

[...] el deporte lo encaramos, no como el deporte para estar prontos para vencer, sino el deporte como arma de bienestar social, que sea accesible a todos los

8 Isso é possível de visualizar nas visitas de Sanguinetti a diversas atividades, como inaugurações, entregas de prêmios etc., durante as quais se realizavam desfiles e cerimônias militares (SODRE. Archivo Presidencial n. A144, min. 23:40 República Oriental del Uruguay, 1990. não publicado)

90 Seminario teve como diretor José Sotelo Fariña, também atuante como Diretor da División Docente e do Departamento de Planificación da CNEF. Este seminário teve como objetivo capacitar docentes em temáticas vinculadas ao currículo, buscando a elaboração de programas curriculares de Educação Física, esporte e recreação para o âmbito não formal (COMISIÓN NACIONAL DE EDUCACIÓN FÍSICA, 1988a).

10 As praças de esporte, espaços amplos com quadras, ginásios e, em alguns casos, piscinas e vestuários, foram criadas a partir de 1912 pela CNEF. Com um importante caráter higienista e eugênico, próprio do positivismo racionalista que marcou a intelectualidade uruguaia do próspero começo de século XX, estas praças foram importante objeto de intervenção das gestões da CNEF. Rodríguez Giménez (2012) e Dogliotti (2012) fizeram importantes estudos sobre elas. 
ciudadanos, y que cada día más personas lo practiquen como acción voluntaria (COMISIÓN NACIONAL DE EDUCACIÓN FÍSICA, 1990, p. 55, grifos nossos).

Claramente a estética corporal de caserna teria que ficar atenuada, pois a efervescência política do momento se via acompanhada por um importante rechaço aos militares ${ }^{11}$. Assim, da homogenização exigida, da submissão a um padrão ideal no qual se desenhava o modelo de ser esportivo, Oriental, patriótico, os programas de Educação Física propostos no retorno à democracia procuravam funcionar permitindo a diferença. A CNEF apresentava uma proposta de Educação Física que tentava unificar a população. Neste sentido, o predomínio da ação governamental se colocava ao lado da inclusão, principalmente pelo convencimento.

Unificar a população será uma tarefa nada simples, e a aparição de um "inimigo" comum que unificasse as distinções emerge com bastante clareza no desenvolvimento do esporte, da Educação Física e da recreação. Trata-se da luta mais ou menos generalizada (pelo menos no plano dos discursos políticos) que supõe diluir as diferenças ideológicas que marcavam fortemente a sociedade, unificando-a frente a um ataque generalizado comum: a luta contra a pobreza e a marginalidade. Procurando "dar cumplimiento a las necesidades prioritarias y básicas de toda la colectividad uruguaya" (COMISIÓN NACIONAL DE EDUCACIÓN FÍSICA, 1990, p. 6) na área do esporte, a Educação Física e a recreação, a CNEF intervinha dando prioridade aos setores com menores possibilidades de contar com um exercício físico programado, "sectores de la ciudad en donde habitan personas de bajos recursos económicos, con difícil acceso a Centros Deportivos y [...] alejadas de nuestras costas y playas." (COMISIÓN NACIONAL DE EDUCACIÓN FÍSICA, 1990, p. 11). Os "setores mais carentes", nomeados em várias oportunidades pela CNEF como público alvo de suas intervenções, testemunham a entrada de um discurso sociológico na política, da mesma forma que os discursos políticos pós-ditatoriais utilizaram o argumento da "vulnerabilidade social", fazendo com que a sociedade se apresentasse como "vítima" de violência, fosse ela generalizada, terrorista, da natureza, na forma de pobreza, doenças etc. (RICO, 2005).

\section{INTEGRAR AO POVO URUGUAIO: O ESPORTE COMO MECANISMO DE SUPERAÇÃO DAS DIFERENÇAS IDEOLÓGICAS}

As praças de esportes, projetadas pela Comisión Nacional de Educación Física em 1912, tiveram um papel fundamental na articulação entre saúde da população e cidadania, aspecto que é fortemente retomado no retorno democrático setenta e três anos depois. A CNEF, estimulando a realização de exercício físico, realizou, no cenário da reconstrução da democracia em 1985, um forte investimento nas praças de esportes da capital e do interior do país. Nelas, o esporte se constituiria como

arma fundamental del bienestar social al estar estrechamente e indisolublemente ligada a la salud, la educación, el uso adecuado del tiempo libre, estilos de vida útiles y al entendimiento entre los miembros de las comunidades e incluso entre ellas (COMISIÓN NACIONAL DE EDUCACIÓN FÍSICA, 1990, p. 46).

\footnotetext{
111983 foi um ano emblemático de repúdio aos militares por parte dos setores não conservadores da sociedade. Situado entre a manifestação popular plebiscitária de 1980, que negara a reforma constitucional proposta pelo governo militar para se perpetuar no poder, e a reinstauração das eleições nacionais em 1984, o ano 1983 tornou-se fundamental na transição. A crescente mobilização política, social e sindical que se vinha gestando a partir da recusa à reforma constitucional manifesta-se de forma evidente nos atos massivos e nas expressões coletivas de resistência. Apagões generalizados, "panelaços" nas ruas, o ato do 1ํ de maio de 1983, as manifestações pelos dez anos do regime ditatorial, a Semana do Estudante em setembro, as manifestações a partir da recuperação democrática na Argentina, o maior ato de massas na história do país, convocado por todos os partidos políticos e que sob a ordem de "Un Uruguay democrático sin exclusiones" realizado no Obelisco de Montevidéu no dia 27 de novembro de 1983, foram algumas da expressões populares de repúdio ao regime e que anunciavam a mudança .
} 
Mas o investimento nas praças também seria salientado pelas gestões ditatoriais. Publicações da CNEF durante esse período destacavam a importância das praças de esportes, afirmando que elas asseguravam serviços dirigidos

a toda la población general: niños, jóvenes, adultos, estudiantes o trabajadores. Nuevas Plazas de Deportes distribuidas en todo el territorio de la República, desarrollan una obra de primordial importancia en la recreación del ciudadano, permitiéndole de forma gratuita realizar una actividad deportiva, que contribuye, en el caso del niño y el joven, a su formación, y en el adulto a compensar un desgaste físico-mental que produce todo trabajo en el hombre. (COMISIÓN NACIONAL DE EDUCACIÓN FÍSICA, 1976, p. 6).

Estes espaços ofereceriam "al educando medios y programas para un mejor aprovechamiento de su tiempo libre" (COMISIÓN NACIONAL DE EDUCACIÓN FÍSICA, 1976, p. 20-21) e para o seu desenvolvimento "físico, moral y espiritual" (COMISIÓN NACIONAL DE EDUCACIÓN FíSICA, 1976, p. 60). O argumento não varia em relação ao propalado pela Comisión, tanto na revista de 1990, quanto nos Programas Curriculares já mencionados. Porém, ainda que o investimento em construções tenha sido salientado durante o governo ditatorial (COMISIÓN NACIONAL DE EDUCACIÓN FÍSICA, 1976), foi muito mais significativo na propaganda do Órgão a realização de competições locais, nacionais e internacionais como forma de "consagrar a los mejores del año en cada actividad [...] [demostrar] que con su contracción al entrenamiento y dedicación, estaban en condiciones aptas para servir de base a las Selecciones Nacionales" (COMISIÓN NACIONAL DE EDUCACIÓN FÍSICA, 1976, p. 38), oferecendo aos jovens a "oportunidad de medir la fuerza de sus músculos" (COMISIÓN NACIONAL DE EDUCACIÓN FÍSICA, 1976, p. 32), e permitindo "no sólo la lucha franca y leal de los alumnos, sino el estrechar los lazos espirituales de nuestra juventud." (COMISIÓN NACIONAL DE EDUCACIÓN FÍSICA, 1976, p. 6).

Com todas essas justificativas, uma das grandes direções tomadas pela CNEF durante o período ditatorial foi a realização de atividades competitivas, dentre as quais se destacam os "Campeonatos Atléticos Deportivos" realizados nas praças de esportes, o "Campeonato Nacional Escolar Atlético - Gimnástico", o "Campeonato Nacional Interplazas de Deportes de Fútbol de Salón", os "Juegos Atléticos Deportivos de Institutos Militares", os "Juegos Atléticos Deportivos Estudiantiles (JADE)", o "Campeonato Nacional Escolar" pelos 250 anos da fundação da cidade de Montevidéu e o "Campeonato 40ํA Aniversario de PLUNA" ${ }^{12 " ~(C O M I S I O ́ N ~ N A C I O N A L ~}$ DE EDUCACIÓN FÍSICA, 1976, p. 52-56), além daquelas atividades vinculadas a cada uma das Federações Esportivas, que tinham a obrigação de realizar pelo menos um evento nacional por ano (COMISIÓN NACIONAL DE EDUCACIÓN FÍSICA, 1976, p. 37).

Com o término da ditadura cívico-militar, o corpo saudável retomará o lugar que fora parcialmente deslocado frente ao privilégio do corpo atlético e militarizado, e o abrangente higienismo voltará como substituto da meticulosidade militar. Se, como indica a CNEF, uma das principais ações durante o período 1985-1990 foi a melhoria dos espaços para o correto desenvolvimento de atividades físicas da população, é porque algo no organismo deve ser preservado. Não já colocando no centro, como fizeram os militares, o espetáculo do corpo e o detalhe no seu aprimoramento, mas acionando a expansão da atividade física a toda a população com um objetivo fortemente higienista. Essa mudança modula o dispositivo disciplinar que na ditadura desenvolve todo o seu potencial, e que a partir da restauração da democra-

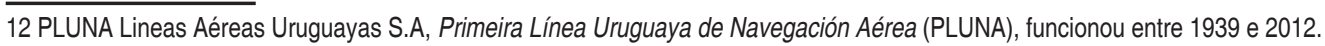


cia encontra suas inflexões, mas não sua desaparição. Do corpo individual ao corpo coletivo, entre disciplina e biopolítica, a ênfase nos dispositivos se acopla ao novo cenário nacional. 0 organismo não deixará de ter um lugar central, mas o acento mudará do detalhe ao bem-estar, conjugando ambas formas de poder na articulação entre vida e política.

Com a "revitalização" das praças de esportes no retorno à democracia, a melhora e construção de "obras no existentes pero imprescindibles" (COMISIÓN NACIONAL DE EDUCACIÓN FÍSICA, 1990, p. 5) para cobrir as "necessidades básicas" da população, se procurava atingir a todos os cidadãos, fazendo a aposta pela via da inclusão e favorecendo os setores com menores possibilidades de realizar práticas sistemáticas de Educação Física. Não sem intenções políticas, a fomento dessas atividades se realizava "acentuando las acciones hacia sectores de menos recursos económicos y/o problemas bio-psico-sociales, discapacitados, 3era edad, marginados, etc. y/o alejados de centros aptos para la práctica deportiva." (COMISIÓN NACIONAL DE EDUCACIÓN FÍSICA, 1990, p. 5).

Marginados econômicos, excluídos territoriais e sociais, serão agora o público frente ao qual se colocará a CNEF, constituindo-os como alteridade a ser incluída nas propostas de esporte, Educação Física e recreação. Inclusão por exclusão, dirá Agamben (2010), se considerarmos que a distinção permanece, a integração é sempre parcial, e sua presença na sociedade apresenta um matiz de marginalidade. Mas se durante a ditadura cívico-militar a alteridade era excluída principalmente pelas visões de mundo ou posições político-partidárias, agora o "outro" será o pobre, a vítima da crise econômica, social e política da qual o país pretende sair, e para a qual o discurso se apresenta como de inclusão. Unificar a população dirigindo os discursos frente a um inimigo comum, ante ao qual as diferenças ideológicas não serão evidentes, será uma via de ação (e manipulação) da palavra política.

É importante esclarecer que o inimigo comum não se concentrava primordialmente nas pessoas, mas na condição na qual alguns setores da sociedade se encontravam. Neste sentido pode-se estabelecer diferenças em relação às ações desenvolvidas durante a ditadura, quando a luta contra o comunismo e as "ideologias estranhas" demarcavam uma divisão na sociedade. Não havia um inimigo comum frente ao qual unificar, senão uma oposição que dividia. A subversão era uma opção voluntária e individual e a ação de governo era contra ela. No caso da pobreza como condição (transitória), o discurso do governo se apresentava a favor dos despossuídos, contra a sua condição, mas, em princípio, não contra as individualidades. Aliás, isso nem sempre supõe que as ações de governo sejam a seu favor; o discurso governamental foi se alterando depois dos primeiros anos da transição, desligando-se o Estado das responsabilidades pela situação econômica crítica desses setores.

O processo de unificação e de apagamento das diferenças ideológicas colocou o esporte como

elemento de desarrollo de una conciencia y cultura, con un profundo sentido humanístico, con respeto a los derechos y sentimientos de los conciudadanos, proponiendo [...] un entendimiento fraterno, y profundo al margen de concepciones políticas, religiosas y sociales. (COMISIÓN NACIONAL DE EDUCACIÓN FISICA, 1990, p. 55).

O discurso integrador será uma forma de difusão e legitimação do poder político, e a CNEF se valeu disso para fundamentar as suas obras, todas elas, segundo indica o diretor num discurso pronunciado em 1985, 
con un sentido muy claro de justicia social, favoreciendo a aquellos sectores que más necesidades tenían, que más alejados estaban de las Playas, que no había Clubes en la zona, y que menos recursos económicos tenían (MAGLIONE ${ }^{13}$ apud COMISIÓN NACIONAL DE EDUCACIÓN FÍSICA, 1990, p. 54).

Se considerarmos as pretensões unificadoras do discurso da CNEF, parece que a neutralidade estaria assegurada e o esporte poderia estar à margem das concepções políticas. Porém, sua independência foi circunstancial. Não muito tempo antes, em 1976, outra publicação da CNEF demarcava sua vinculação com o regime militar, numa revista que de forma ampla e detalhada apresentava as ações desenvolvidas nesses anos e procurava dar "publicidad de los eventos organizados, auspiciados o patrocinados por el Organismo, así como la propaganda sobre su política y la acción desplegada tendiente a obtener el beneficio nacional, en el marco de la doctrina de desarrollo del Estado." (COMISIÓN NACIONAL DE EDUCACIÓN FÍSICA, 1976, p. 78). Dessa propaganda do regime, pouco tempo depois se passou a afirmar a possibilidade do esporte se manter "al margen de concepciones políticas, religiosas y sociales" (COMISIÓN NACIONAL DE EDUCACIÓN FÍSICA, 1990, p. 5), assinalando os caminhos da CNEF para levar a Educação Física, o esporte e a recreação a todos os cidadãos, sem distinções políticas.

O devir do esporte não é alheio ao devir político. Sabemos dos efeitos políticos do esporte, e que onde se proclama neutralidade se escondem arbitrariedades. Não por acaso todo grande acontecimento político encontrou-se, mais o menos de perto, acompanhado por grandes mobilizações esportivas. Distração das massas, unificação do povo, exaltação da raça, supremacia do mais forte, de indivíduos e de nações, foram alguns dos mais empregados usos políticos do esporte, em maior ou menor medida, especialmente nos anos da Guerra Fria e um pouco antes dela. Desde muito o esporte, como fenômeno moderno, manteve suas vinculações com as intenções de governos. Governo indireto das pulsões, forma direta de descarga de excessos corporais; jogadores e espectadores, tanto uns quanto outros se entregam ao esporte num gesto que inclui, por si, a ficção da política.

\section{CONSIDERAÇÕES FINAIS}

O retorno à democracia no Uruguai, depois de quase doze anos de governo ditatorial, não chegou com uma mudança radical nas formas de articulação entre o corpo e a política. Novidades nas propostas se conjugaram com a renovação de dispositivos, aparentando mudanças mas também facilitando vias de continuidade entre as formas de governo.

Ênfase no recondicionamento das praças de esportes, assim como na promoção de espaços destinados à prática de atividades esportivas, recreativas e de Educação Física foram as principais propagandas das gestões realizadas pela CNEF durante o período pós-ditatorial (1985-1990). Sua principal justificativa era brindar espaços democráticos e democratizantes, que superassem as diferenças políticas que até então dividiam a sociedade. O esporte será, assim, concebido como uma prática unificadora e de coesão social, e será reivindicada a maior participação possível de todos os setores sociais nestes espaços, com um discurso integrador que avalia a si mesmo como democrático e pacificador. A unificação da sociedade se tornou palavra de ordem nos discursos governamentais de reconstrução democrática, em consonân- 
cia com as tentativas de "mudança em paz" e "pacificação".

As intervenções vinculadas à Educação Física na redemocratização do Uruguai, a partir de 1985, aparentam afastar-se das formas violentas de governar, porém, mantiveram um núcleo irredutível quando se considera que o governo é do corpo, ou seja, tendo o organismo como alvo das decisões. Uma política que se orienta pelos parâmetros da economia, reduzindo o corpo às definições biologicistas e proclamando a atividade física como via de superação das diversidades políticas permite alcançar um encapsulamento do espaço da política, da ação e do discurso, que é submetido aos silêncios da administração, à gestão das necessidades, ou simplesmente, à voz, não mais à palavra.

\section{REFERÊNCIAS}

AGAMBEN, G. Homo Sacer: o poder soberano e a vida nua I. Belo Horizonte: UFMG, 2010.

BAILÓN, M. 1975: año de la orientalidad. el cuerpo/moral en el proceso de reorganización nacional. Educação Temática Digital, Campinas, v. 8, n. esp, p. 290-313, jun. 2007.

BUQUET, D. Elecciones y Sistema electoral. In: INSTITUTO DE CIENCIA POLITICA. EI Uruguay del Siglo XX. Montevideo: Ediciones de la Banda Oriental, 2003. v. 2: La política. p. 137-171.

CAETANO, G. Marco histórico y cambio político en dos décadas de democracia. De la transición democrática al gobierno de izquierda (1985-2005). In: CAETANO, G. (Dir). 20 años de democracia, Uruguay 1985 - 2005: miradas múltiples. Montevideo: Taurus, 2005. p. 15-76.

CAETANO, G; RILLA, J. Breve historia de la dictadura. Montevideo: CLAEH-EBO, 1987. 175p.

COMISIÓN NACIONAL DE EDUCACIÓN FÍSICA. El deporte, la educación física y la recreación: marzo 1985-Marzo 1990. Montevideo: [s.n.], 1990. 57p.

COMISIÓN NACIONAL DE EDUCACIÓN FÍSICA. Programa de educación deportiva. Montevideo: Nueva Impresora Piscis, 1988a. 62 p.

COMISIÓN NACIONAL DE EDUCACIÓN FÍSICA. Programa de educación física: nivel medio. Montevideo: Nueva Impresora Piscis, 1988b. 18p.

CONSEJO NACIONAL DE EDUCACIÓN. Cuadernos de Educación Física № 2. Tema de la Bonilla № 5. Montevideo: Impresos de Educación Secundaria Básica y Superior, 1980.

DEMASI, C. La evolución del campo político en la dictadura. In: DEMASI, C. et al. La dictadura cívico-militar: Uruguay 1973-1985. Montevideo: Banda Oriental, 2013. p. 15-115.

DOGLIOTTI, P. Cuerpo y currículum: discursividades en torno a la formación de docentes de educación física en Uruguay (1874-1948). 2012a. 324f. Dissertação (Mestrado em Ensino Universitário) - Universidad de la República, Montevideo (Uruguay). Disponível em: <http://posgrados. cse.edu.uy/sites/posgrados.cse.edu.uy/files/tesis_paola_dogliotti.pdf>. Acesso em 2014.

FOUCAULT, M. Vigiar e punir: nascimento da prisão. Petrópolis: Vozes, 1997. 262 p.

MARCHESI, A. El Uruguay inventado: la política audiovisual de la dictadura, reflexiones sobre su imaginario. Montevideo: Ediciones Trilce, 2001.

RICO, A. Como nos domina la clase gobernante: orden político y obediencia social en la democracia posdictadura, Uruguay 1985-2005. Montevideo: Trilce. 2005.

RODRÍGUEZ GIMÉNEZ, R. Saber del cuerpo: una exploración entre normalismo y universidad en ocasión de la educación física (Uruguay 1876-1939). Montevideo (Uruguay). 2012. 262f. Dissertação (mestrado em Ensino Universitário). Universidad de la República, UdelaR. Disponível em: http:// posgrados.cse.edu.uy/sites/posgrados.cse.edu.uy/files/tesis_raumar_rodriguez.pdf 
RODRÍGUEZ GIMÉNEZ, R. Escenas del cuerpo militarizado en el Uruguay de la dictadura (19731985). In: ROZENGARDT, R. (Org). Apuntes de historia para profesores de educación física. Buenos Aires: Miño y Dávila, 2006. p. 145-158.

RODRÍGUEZ GIMÉNEZ, R. Educación Física y dictadura: el cuerpo militarizado. Revista Brasileira Ciências do Esporte, Campinas, v. 25, n. 1, p. 101-113, set. 2003.

URUGUAY. Ley no 15.848 , de 28/12/1986. Funcionarios militares y policiales. Se reconoce que ha caducado el ejercicio de la pretensión punitiva del Estado respecto de los delitos cometidos hasta el 1ํ de marzo de 1985. Disponível em: <http://www.parlamento.gub.uy/leyes/AccesoTextoLey. asp?Ley=15848>. Acesso: 30 de set. 2013.

URUGUAY. Ley no 14.101, de 04/01/1973. Disponível em: <http://www.parlamento.gub.uy/leyes/ AccesoTextoLey.asp?Ley=14101\&Anchor=>. Acesso: 20 de janeiro de 2014.

URUGUAY. Ministério de Educación y Cultura. Comisión Nacional de Educación Fisica. Montevideo: Polo, 1976.

\section{Endereço para correspondência:}

Universidade Federal de Santa Catarina - Centro de Ciências da Educação

Campus Reitor João David Ferreira Lima - Bairro Trindade

CEP 88040-970 - Florianópolis - SC - Brasil.

Apoio financeiro do CNPq: Programa de Pesquisa Teoria Crítica, Racionalidades e Educação IV; bolsa de produtividade em pesquisa; bolsa mestrado do Programa Estudantes-Convênio de Pós-Graduação. 